\title{
BIOLOGIA REPRODUTIVA DE Acacia mearnsii DE WILD. (FABACEAE) IV: VISITANTES FLORAIS ${ }^{1}$
}

\author{
Eudes Maria Stiehl Alves² e Maisa Pimental Marins-Corder ${ }^{3}$
}

\begin{abstract}
RESUMO - Para que as estratégias de melhoramento genético em espécies arbóreas tenham sucesso, o conhecimento da biologia reprodutiva da espécie envolvida é indispensável. Um dos fatores críticos ao sucesso reprodutivo das espécies do gênero Acacia é a presença de vetores para a polinização. Os objetivos deste trabalho foram identificar os visitantes florais em um plantio comercial de Acacia mearnsii De Wild. e quantificar as políades aderidas à superfície corporal dos insetos. As observações foram realizadas em uma torre localizada no plantio comercial durante o período de floração de 2002 e 2003. Os visitantes florais foram capturados no período diurno com o auxílio de rede entomológica e de um cesto aéreo instalado em um trator. No período noturno, os insetos foram capturados com o auxílio de armadilhas luminosas instaladas entre as copas florescidas. Foram observados insetos pertencentes às ordens Coleoptera, Hymenoptera, Diptera, Hemiptera e Lepidoptera. Os besouros da espécie Macrodactylus suturalis foram considerados como dispersores do pólen de acácia-negra, pela alta frequência de indivíduos presentes no povoamento estudado e pela grande quantidade de políades aderidas no corpo dos insetos capturados ( $\mathrm{X}=229,36$ políades/inseto). As abelhas da espécie Apis mellifera, embora tenha sido quantificada uma grande quantidade de políades nos indivíduos capturados ( $\mathrm{X}=448,50$ políades/ inseto), não foram observadas com frequência na área analisada. Uma das formas recomendadas para aumentar a frequência de abelhas e vespas nos plantios comerciais de acácia-negra é a manutenção de fontes de néctar e a introdução de caixas com abelhas A. mellifera.
\end{abstract}

Palavras-chave: Acácia-negra, polinização e Macrodactylus suturalis.

\section{REPRODUCTIVE BIOLOGY OF Acacia mearnsii DE WILD. (FABACEAE) IV: FLOWER VISITORS}

\begin{abstract}
To ensure the success of the strategies of genetic improvement in tree species, knowledge of the reproductive biology of the species involved is essential. One of these critical factors in reproductive success of the genus Acacia is the presence of vectors to pollination. The purpose of this study was to identify flower visitors to a commercial plantation of Acacia mearnsii De Wild. and quantify the polyads attached to the body surface of the insects. The observations were made from a tower in a commercial stand during flowering, in 2002 and 2003. During the day, flower visitors were captured with an entomological net and an air basket installed on a tractor. At night, insects were caught with light traps installed between the flowering crowns. Insects belonging to orders Coleoptera, Hymenoptera, Diptera, Hemiptera and Lepidoptera were observed. Beetles of the species Macrodactylus suturalis were considered dispersers of black wattle pollen, based on the high frequency of individuals in the population studied and the high quantity of polyads adhered to the body of the caught insects ( $X=229,36$ polyads/insect). The amount of polyads verified on bees of the species Apis mellifera was significantly greater $(X=448,50$ polyads/insect), but the frequency in the study area was insignificant. One of the recommended ways to increase the frequency of bees and wasps in black-watle commercial plantations is the maintenance of sources of nectar and the introduction of bee hives.
\end{abstract}

Keywords: Black-wattle, pollination and Macrodactylus suturalis.

\footnotetext{
${ }^{1}$ Recebido em 04.07.2007 e aceito para publicação em 24.04.2009.

${ }^{2}$ Programa de Pós-Graduação em Genética e Biologia Molecular da Universidade Federal do Rio Grande do Sul (UFRGS). E-mail: <eudesmsalves@yahoo.com.br>.

${ }^{3}$ Departamento de Ciências Florestais da Universidade Federal de Santa Maria (UFSM). E-mail: <misapm@gmail.com>.
} 


\section{INTRODUÇÃO}

As informações reunidas através da análise da biologia reprodutiva em espécies florestais são fundamentais para que as estratégias dos programas de melhoramento genético tenham sucesso. Em se tratando de espécies florestais com valor econômico, como é o caso de $A$. mearnsii, uma espécie com amplo potencial econômico por sua múltipla utilidade na indústria de couros e produtos químicos (CALDEIRA et al. 2003; PAULINO et al., 2003), o controle da reprodução se justifica pela melhoria do germoplasma, resultando na produção contínua de sementes de qualidade, de indivíduos sadios e com bom desenvolvimento e culminando com a padronização do produto a ser comercializado.

A acácia-negra é uma espécie em que as inflorescências ocorrem em racemos axilares que contêm aproximadamente 50 flores de tonalidade amarelo-clara, as quais são fortemente perfumadas (GRANT et al., 1994). De acordo com esses autores, nessa espécie podem ser encontradas flores hermafroditas ou funcionalmente masculinas. Dezesseis grãos de pólen encontram-se agregados em uma estrutura de políade. Durante a antese, as anteras bilobadas se abrem em fenda, protraindo as políades através de fendas verticais (GRANT et al., 1994; KENRICK e KNOX, 1979).

No gênero Acacia, os insetos da ordem Hymenoptera foram indicados como os principais vetores da polinização, embora outros insetos e pássaros possam estar envolvidos na transferência dos grãos-de-pólen (BERNHARDT et al., 1984; SORNSATHAPORNKUL e OWENS, 1998; WAGNER, 2000; TANDON et al., 2001). Em Acacia retinodes foram observadas algumas espécies de abelhas (Hymenoptera) como as principais responsáveis pela polinização, ainda que insetos das ordens Diptera e Coleoptera também tenham sido observados visitando as inflorescências (BERNHARDT et al., 1984). O coleóptero Mylabris pustulata foi visto como o principal dispersor de pólen em inflorescências de Acacia senegal, embora esse coleóptero também tenha sido observado predando os órgãos florais dessa espécie (TANDON et al., 2001).

A identificação das espécies de insetos e dos hábitos dos visitantes florais durante o período do florescimento de espécies arbóreas contribui com informações que permitem que sejam feitas estimativas sobre o fluxo de pólen entre os indivíduos arbóreos aptos reprodutivamente e o controle das populações de insetos durante o florescimento. O resultado final dessas estratégias é a maximização da produção de sementes em espécies florestais. Dessa forma, o objetivo deste estudo foi identificar os agentes envolvidos no fluxo polínico de $A$. mearnsii, através da captura de insetos e da contagem das políades aderidas na superfície corporal.

\section{MATERIAL E MÉTODOS}

O estudo foi conduzido em uma área de plantio comercial de propriedade da empresa AGROSETAS.A., localizado na Fazenda Menezes, Município de Butiá, Rio Grande do Sul. Nesse plantio comercial foi instalada uma torre de $16 \mathrm{~m}$ de altura para observações das copas floridas. Com a finalidade de verificar o tipo, a periodicidade e a frequiência dos insetos, foram realizadas observações prévias da sua atividade semanalmente durante o período de florescimento do ano de 2002 (agosto a novembro). Em auxílio às verificações realizadas sobre a torre, em 2002 também foi utilizada uma trilha no interior do plantio comercial, na qual foram observadas 32 árvores de acácia-negra distantes entre si $50 \mathrm{~m}$. No ano de 2003, as observações foram realizadas semanalmente sobre a torre nos meses de setembro e outubro. Depois de verificada a periodicidade e frequência dos visitantes florais, realizou-se a captura dos insetos sobre as inflorescências, durante o período de pico do florescimento (segunda semana do mês de setembro de 2003).

As copas das árvores próximas à torre de observação foram visualizadas com o auxílio de um binóculo (10 $x$ 50). Os insetos foram capturados nas inflorescências localizadas nas copas das árvores com o auxílio de um trator contendo um cesto aéreo e de rede entomológica. O período diurno de observações (anos de 2002 e 2003) compreendeu o seguinte horário: i) $8 \mathrm{~h}$ da manhã até $11 \mathrm{~h}$; e, ii) das 15 até as $18 \mathrm{~h}$ (seis horas diurnas de observações). No período diurno foram selecionados seis pontos aleatórios em locais sombreados das copas, os quais foram observados por um período de $20 \mathrm{~min}$ cada, em que se registrou o tipo de atividade realizado pelos insetos: predação, passeio ou cópula. O número total de árvores localizadas imediatamente ao redor da torre de observações foi de 15 .

Em 2003 também foram feitas observações no período noturno durante a fase de máximo florescimento da acácia-negra (segunda semana do mês de setembro), 
das 19 h até $1 \mathrm{~h}$ da manhã, em um total de $30 \mathrm{~h}$. A atividade noturna dos insetos foi registrada através da utilização de binóculo e com o auxílio de uma lanterna. Também foram suspensas armadilhas luminosas entre as copas floridas, as quais serviram para a captura dos insetos. Após as coletas (diurnas e noturnas), os insetos foram mortos com o auxílio de clorofórmio e acondicionados em frascos de vidro individuais.

A identificação dos visitantes florais foi feita no Laboratório de Entomologia (Departamento de Defesa Fitossanitária)/Universidade Federal de Santa Maria. $\mathrm{O}$ acondicionamento para a análise e armazenamento dos visitantes florais capturados foi realizado no Laboratório de Biotecnologia Florestal (UFSM). A contagem das políades aderidas na superfície corporal dos visitantes florais foi realizada com o auxílio de estereoscópio e microscópio óptico. A coleção de visitantes florais foi acondicionada em geladeira na temperatura de $4{ }^{\circ} \mathrm{C}\left( \pm 2{ }^{\circ} \mathrm{C}\right)$.

\section{RESULTADOS E DISCUSSÃO}

\subsection{Identificação e hábito dos visitantes florais capturados}

Foram capturados sobre as copas floridas de indivíduos de $A$. mearnsii insetos representantes de cinco ordens: Coleoptera, Hemiptera, Hymenoptera, Diptera e Lepidoptera. Da ordem Coleoptera foram identificados visitantes florais pertencentes a três famílias: i) Scarabaeidae, uma espécie identificada ( $M$. suturalis, subfamília Melolonthinae) e duas subfamílias identificadas (Coprinae e Aphodiinae); ii) Coccinellidae; e iii) Cerambycidae, três identificações em nível de espécie e uma identificação em nível de subfamília. O hábito alimentar predominante dos besouros das famílias Scarabaeidae, Coccinellidae e Cerambycidae capturados para este estudo é fitófago, com importância econômica na agricultura e na silvicultura pelas perdas que ocasionam. No caso dos insetos da família Cerambycidae, subfamília Cerambycinae, na fase adulta o seu hábito alimentar inclui flores e inflorescências.

Os visitantes florais da ordem Hemiptera foram identificados em nível de família: Reduviidae e Pentatomidae (hábito alimentar fitófago). Da ordem Hymenoptera foram identificados os visitantes florais representantes de três famílias: i) Apidae, com hábito alimentar melífero e nectarífero; ii) Vespiidae, subfamílias Braconidae (parasitas de larvas de mariposas noturnas, dípteros e besouros xilófagos); e iii) Mutillidae (parasitas externos de besouros, moscas e de larvas de vespas), Polybiinae e Vespinae (ambas de hábito melífero e nectarífero). Os visitantes florais de duas famílias da ordem Diptera foram identificados: Dolichopodidae e Empididae (predadores de outras espécies de insetos). Da ordem Lepidoptera foram capturadas mariposas da família Noctuidae.

No período de observação, a atividade dos visitantes florais começou a ser registrada a partir do horário das nove horas da manhã, quando alguns representantes das ordens Diptera e Hymenoptera foram vistos sobrevoando a área das copas das árvores. A atividade dos visitantes florais começou a diminuir a partir das $11 \mathrm{~h}$ da manhã, quando a temperatura aumentou consideravelmente. Embora a atividade tenha se reduzido nesse horário, insetos da ordem Lepidoptera foram vistos sobrevoando as copas das árvores constantemente ao longo do dia sem pousar, possivelmente para a corte. Foram identificados pares de lepidópteros voando em atitude de cópula. Os insetos visitantes das ordens Diptera e Hymenoptera foram observados sobrevoando as copas das árvores solitariamente ou em enxames. Foram observados alguns indivíduos solitários da ordem Hymenoptera em atitude que sugeriu um hábito territorialista e possivelmente predador. Esses insetos não foram vistos pousando sobre as inflorescências. Os insetos que sobrevoavam as inflorescências em enxames foram observados pousando sobre as flores por alguns segundos.

Os visitantes florais da ordem Coleoptera, família Cerambycidae (Trachyderes sp. e Compsocerus violaceus) foram vistos predando ativamente as inflorescências de acácia-negra. Os besouros da espécie $M$. suturalis (família Scarabaeidae) exibiram padrão de comportamento que consistiu em percorrerem diversas inflorescências de um mesmo ramo de acácia-negra, seguindo para outros ramos da mesma árvore ou de árvores vizinhas. Alguns indivíduos foram vistos alimentando-se de folhas, mas a maioria o foi sobre as inflorescências. Foram observados indivíduos de $M$. suturalis em atitude de cópula sobre as inflorescências. A hipótese para esse comportamento é de que as fêmeas dessa espécie utilizaram os ramos floridos da acácia-negra para atraírem os machos, visto que o fundo de tonalidade amarelada das inflorescências permitiu o destaque desses insetos de coloração escura. A mudança contínua de ramos pode indicar atitude de escape a predadores, uma vez

R. Árvore, Viçosa-MG, v.33, n.3, p.443-450, 2009 
que as fêmeas, ao utilizarem a tonalidade clara das inflorescências para a atração de indivíduos masculinos de $M$. suturalis, ficariam expostas ao ataque de predadores.

Nas observações noturnas, embora tenham sido notado mariposas (Lepidoptera) sobrevoando as inflorescências de acácia-negra, a intensidade luminosa da lanterna e do trator utilizado nas coletas pode ter atraído esses insetos. Foram coletados em armadilha luminosa mariposas (Lepidoptera, Noctuidae), um coleóptero da subfamília Coprinae e dois indivíduos da ordem Hemiptera (Pentatomidae).

\subsection{Quantificação das políades na superfície corporal dos insetos}

Nos visitantes florais da ordem Coleoptera foram observados 73,13\% (6.470 políades) do total de políades quantificadas em todas as ordens coletadas (Tabela 1). Em relação às políades observadas em insetos capturados da ordem Coleoptera, na família Scarabaeideae foi observado $91,87 \%$ das políades quantificadas. Em coleópteros da espécie M. suturalis (Scarabaeideae, Melolonthinae) foi observada a maior quantidade de políades de acácia-negra (Figura 1AB), tanto em relação à quantidade total observada $(64,81 \%)$ quanto à quantidade dentro da ordem Coleoptera $(88,62 \%)$. Possivelmente, a época de reprodução desses insetos coincidiu com o período do florescimento da A. mearnsii, o que foi reforçado pelo fato de que vários indivíduos de $M$. suturalis foram observados e capturados em atitude de cópula sobre as inflorescências da acácianegra. Também foi notado diferença na contagem de políades na superfície corporal de insetos de $M$. suturalis, ou seja, nos 25 insetos amostrados a contagem variou de cerca de uma centena até aproximadamente 500 políades por besouro $(\bar{X}=229,36)$. Os visitantes florais da espécie M. suturalis têm como hábito alimentar a ingestão de folhas, o que foi comprovado pelas observações em A. mearnsii. Outras espécies do gênero Macrodactylus são consideradas como importantes pragas da agricultura e da silvicultura: Macrodactylus subspinosus (WILLIANS et al., 2000); Macrodactylus nigripes, em plantações de milho (Zea mays L.) e em parreirais (Vicia faba L.) localizadas no México (CASELÍN-CASTRO et al., 2003); Macrodactylus costulatus, identificado em florestas tropicais e em várias culturas de clima tropical localizadas em Honduras (ARCE-PÉREZ e MORÓN, 2005); e Macrodactylus sericeicollis e Macrodactylus sericinus, em plantações de café localizadas na Guatemala e na Nicarágua (ARCE-PÉREZ e MORÓN, 2005).

Tabela 1 - Relação de visitantes florais capturados em inflorescências de $A$. mearnsii, número total, número médio e porcentagem de políades observadas

Table 1 - List of captured flower visitors on inflorescences of A. mearnsii, total number, mean number and percentage of polyads observed

\begin{tabular}{|c|c|c|c|c|c|c|}
\hline \multirow[t]{2}{*}{ Ordem, família e subfamília } & \multirow[t]{2}{*}{ Espécie } & \multirow{2}{*}{$\begin{array}{l}\text { Número de } \\
\text { insetos } \\
\text { capturados }\end{array}$} & \multirow{2}{*}{$\begin{array}{l}\text { Número total } \\
\text { de políades } \\
\text { quantificadas }\end{array}$} & \multirow{2}{*}{$\begin{array}{c}\text { Média de } \\
\text { políades } \\
\text { quantificadas }\end{array}$} & \multicolumn{2}{|c|}{$\begin{array}{c}\text { Porcentagem } \\
\text { de políades observadas }\end{array}$} \\
\hline & & & & & $\begin{array}{c}\text { Em relação } \\
\text { à ordem }\end{array}$ & $\begin{array}{c}\text { Em relação } \\
\text { ao total }\end{array}$ \\
\hline \multicolumn{7}{|l|}{ COLEOPTERA } \\
\hline Scarabaeidae (Melolonthinae) & Macrodactylus suturalis & 25 & 5.734 & 229,36 & 88,62 & 64,81 \\
\hline Scarabaeidae (Coprinae) & Não identificado & 1 & 2 & 2,00 & 0,03 & 0,02 \\
\hline Scarabaeidae (Aphodinae) & Não identificado & 8 & 208 & 26,00 & 3,21 & 2,35 \\
\hline Coccinellidae & Não identificado & 2 & 20 & 10,00 & 0,31 & 0,23 \\
\hline Cerambycidae & Trachyderes dimiatus & 1 & 113 & 113,00 & 1,75 & 1,28 \\
\hline Cerambycidae & Trachyderes striatus & 1 & 15 & 15,00 & 0,23 & 0,17 \\
\hline Cerambycidae (Cerambycinae) & Compsocerus violaceus & 2 & 312 & 156,00 & 4,82 & 3,53 \\
\hline \multirow[t]{2}{*}{ Cerambycidae (Cerambycinae) } & Não identificado & 1 & 66 & 66,00 & 1,02 & 0,75 \\
\hline & TOTAL & 41 & 6.470 & 157,80 & & 73,13 \\
\hline \multicolumn{7}{|l|}{ DIPTERA } \\
\hline Dolichopodidae & Não identificado & 1 & 58 & 58,00 & 21,48 & 0,66 \\
\hline \multirow[t]{2}{*}{ Empididae } & Não identificado & 2 & 270 & 135,00 & 82,32 & 3,05 \\
\hline & TOTAL & 3 & 328 & 109,33 & & 3,71 \\
\hline
\end{tabular}

R. Árvore, Viçosa-MG, v.33, n.3, p.443-450, 2009 
Tabela 1 - Cont.

Table 1 - Cont

\begin{tabular}{|c|c|c|c|c|c|c|}
\hline \multirow[t]{2}{*}{ Ordem, família e subfamília } & \multirow[t]{2}{*}{ Espécie } & \multirow{2}{*}{$\begin{array}{l}\text { Número de } \\
\text { insetos } \\
\text { capturados }\end{array}$} & \multirow{2}{*}{$\begin{array}{l}\text { Número total } \\
\text { de políades } \\
\text { quantificadas }\end{array}$} & \multirow{2}{*}{$\begin{array}{c}\text { Média de } \\
\text { políades } \\
\text { quantificadas }\end{array}$} & \multicolumn{2}{|c|}{$\begin{array}{c}\text { Porcentagem } \\
\text { de políades observadas }\end{array}$} \\
\hline & & & & & $\begin{array}{c}\text { Em relação } \\
\text { à ordem }\end{array}$ & $\begin{array}{c}\text { Em relação } \\
\text { ao total }\end{array}$ \\
\hline \multicolumn{7}{|l|}{ HEMIPTERA } \\
\hline Reduvidae & Melanolestes sp. & 3 & 224 & 74,67 & 100,00 & 2,53 \\
\hline \multirow[t]{2}{*}{ Pentatomidae } & Não identificado & 2 & 0 & 0,00 & 0,00 & 0,00 \\
\hline & TOTAL & 5 & 224 & 44,80 & & 2,53 \\
\hline \multicolumn{7}{|l|}{ HYMENOPTERA } \\
\hline Apidae (Apinae) & Apis mellifera & 2 & 897 & 448,50 & 49,50 & 10,14 \\
\hline Vespidae (Polybiinae) & Não identificado & 1 & 16 & 16,00 & 0,88 & 0,18 \\
\hline Vespidae (Vespinae) & Não identificado & 11 & 604 & 54,91 & 33,33 & 6,83 \\
\hline Vespidae (Mutillidae) & Não identificado & 20 & 104 & 5,20 & 5,74 & 1,18 \\
\hline \multirow[t]{2}{*}{ Vespidae (Braconidae) } & Não identificado & 2 & 191 & 95,50 & 10,54 & 2,16 \\
\hline & TOTAL & 36 & 1812 & 50,33 & & 20,48 \\
\hline \multicolumn{7}{|l|}{ LEPIDOPTERA } \\
\hline \multirow[t]{2}{*}{ Noctuidae } & Não identificado & 25 & 13 & 0,52 & 100,00 & 0,15 \\
\hline & TOTAL & 25 & 13 & 0,52 & & 0,15 \\
\hline & TOTAL GERAL & 110 & 8.847 & 80,43 & & \\
\hline
\end{tabular}

Na família Cerambycidae foram observadas 506 políades do total amostrado na ordem Coleoptera. Notavelmente, na espécie $C$. violaceus (subfamília Cerambycinae) foram quantificadas 312 políades (Tabela 1). Na espécie T. dimiatus, (subfamília Cerambicinae) foram amostradas 113 políades. A grande quantidade de políades encontradas no corpo de $C$. violaceus e de T. dimiatus pode estar relacionada ao hábito alimentar exibido por essas espécies, que são preferencialmente fitófagas e especialmente ávidas por inflorescências (Figura 1CD). As duas espécies foram observadas em atividade de predação em inflorescências de acácianegra. Ao ingerirem as inflorescências, os insetos contaminaram-se com as políades, contribuindo indiretamente com a polinização de $A$. mearnsii ao levarem os grãos de pólen para outros ramos contendo flores a serem atacadas.

$\mathrm{Na}$ ordem Hymenoptera foram observadas 1.812 políades $(20,48 \%$ do total de políades amostradas). Na família Vespidae foi observado 50,50\% (915 políades) do total quantificado na ordem Hymenoptera (Tabela 1). Embora essa família tenha contribuído com quase a metade de políades observadas nessa ordem (Figura $1 \mathrm{EF}$ ), deve-se levar em consideração o fato de que foram capturados insetos pertencentes a quatro subfamílias: Polybiinae, Vespinae, Mutillidae e Braconidae. No caso da família Apidae, foram capturadas apenas duas abelhas da espécie $A$. mellifera, nas quais foi observado $49,50 \%$ (897 políades) do total quantificado na ordem
Hymenoptera (Figura 1GH), o que correspondeu a 10,14\% do total geral de políades verificadas em todos os insetos coletados. Nas vespas capturadas da subfamília Vespinae foram observadas 604 políades. Embora o número de políades quantificadas nos insetos capturados dessa subfamília tenha sido expressivo, houve indícios de superestimativa desse valor, visto que em apenas uma vespa foram contadas 418 políades. Esse erro amostral pode estar associado à contaminação no momento da coleta por políades aderidas à rede.

Embora nos dois indivíduos capturados de $A$. mellifera tenha sido quantificada grande proporção de políades, a densidade desses insetos no plantio comercial estudado pode ser considerada baixa quando comparada à de $M$. suturalis, de acordo com as observações realizadas. A frequência dessas abelhas também foi menor quando comparada com a de vespas da subfamília Vespinae (Tabela 1). De acordo com os resultados, foi observado que a polinização da acácia-negra ocorreu de maneira acidental quando os insetos observados com maior freqüência se encontravam envolvidos na atração para a cópula (caso específico de $M$. suturalis), na predação de inflorescências (Trachyderes sp. e C. violaceus) ou na caça a outros insetos.

A possibilidade de existirem outros recursos alimentares com maior recompensa localizados próximo aos talhões comerciais possivelmente tem influência na escolha da vegetação a ser visitada pelas abelhas e vespas na busca por alimento. No caso de $A$. mellifera,

R. Árvore, Viçosa-MG, v.33, n.3, p.443-450, 2009 
o hábito alimentar é considerado nectarífero e melífero. O néctar é uma fonte rica em açúcares e água, e nas espécies do gênero Acacia, subgênero Phyllodineae (incluindo a $A$. mearnsii) não foi constatada a produção dessa secreção (STONE et al., 2003). A A. mearnsii possui nectários extraflorais localizados no pecíolo foliar, os quais têm como principal finalidade a atração de formigas para a defesa biótica contra a herbivoria (MONCUR et al., 1991; STONE et al., 2003). O conteúdo de açúcares encontrado nos nectários extraflorais da acácia-negra foi estimado em 40\% (MONCUR et al., 1991). Quanto ao coleóptero $M$. suturalis, o seu hábito alimentar é fitófago, e esse inseto tem o recurso alimentar assegurado nas folhas de $A$. mearnsii. De acordo com as observações deste estudo, o coleóptero possivelmente utilizou a área florida da copa como estratégia para a reprodução.

A preferência por outras fontes alimentares por A. mellifera já foi observada por Charão (2000) ao analisar o efeito da polinização por esses insetos em A. mearnsii, através da introdução de caixas contendo abelhas em áreas de plantio comercial localizadas nas proximidades do Município de Butiá, RS. Nesse estudo, amostras de pólen foram coletadas das patas das abelhas para registro por eletrofotomicrografia por varredura. Através do registro fotográfico, o referido autor identificou grande quantidade de grãos de pólen de Eucalyptus sp. provenientes, provavelmente, de plantios comerciais dessa espécie localizados nas imediações dos povoamentos de acácia-negra. Políades de $A$. mearnsii foram encontradas em menor quantidade nessas amostras. Outro exemplo da falta de fidelidade na coleta de pólen de acácias por $A$. mellifera foi observada em $A$. retinodes (subgênero Phyllodineae), em que $62 \%$ das abelhas capturadas e analisadas através de microscopia óptica continham em seu corpo grãos de pólen de outras espécies produtoras de néctar, como Hypochaeris radicata, Lycium ferocissimum, Salpichroa origanifolia e Melaleuca lanceolata (BERNHARDT et al., 1984). Neste estudo, embora não tenham sido consideradas como visitantes fiéis algumas espécies da ordem Hymenoptera, A. mellifera, Lasioglossum spp. e Megachile spp., elas foram tidas como consistentes e como vetores da polinização.

Ao estudarem o sistema de reprodução de populações naturais de $A$. mearnsii localizadas em New South Wales (Austrália), Grant et al. (1994) introduziram caixas contendo cerca de 400.000 indivíduos de $A$. mellifera. De acordo com esses autores, a presença desses polinizadores potenciais não teve efeito significativo na quantidade de estigmas polinizados e na produção de vagens. Entre as espécies florestais que ocorriam em conjunto com $A$. mearnsii nesse estudo estavam Eucalyptus dives e Eucalyptus pauciflora. Além disso, na pesquisa realizada por Grant et al. (1994) não foram qualificados e quantificados os grãos de pólen presentes nas abelhas após a sua introdução nas populações de acácia-negra.

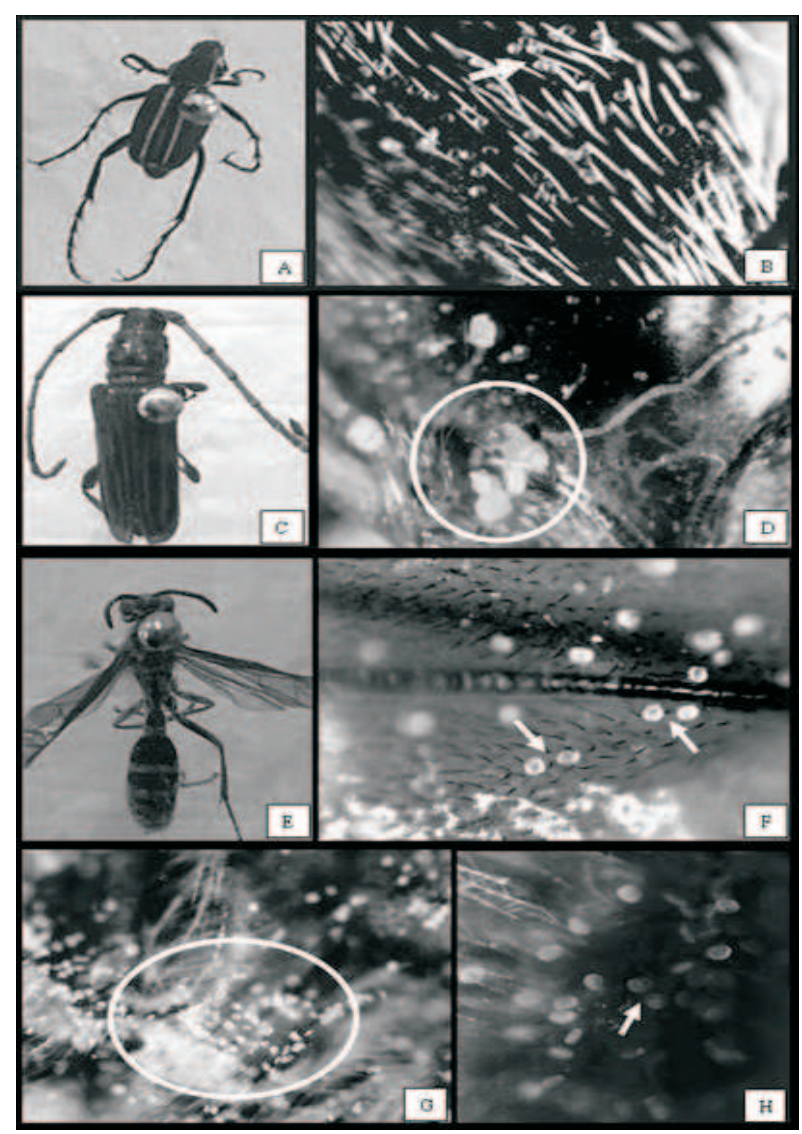

Fonte: BIOFLOR/UFSM

Figura 1 - Insetos capturados em inflorescências de A. mearnsii. A-B) M. suturalis (Coleoptera, Scarabaeidae); CD) T. dimiatus (Coleoptera, Cerambycidae); EF) Vespa da família Vespidae (Hymenoptera); G$\mathrm{H})$ Detalhe do corpo de um indivíduo de $A$. mellifera mostrando as políades de acácia-negra aderidas. B, D, F e H) Detalhes com aumento de 10 vezes em microscopia óptica. As setas (B, F e H) e o círculo brancos $(\mathrm{G})$ indicam políades de acácianegra aderidas ao corpo dos insetos. Em (D), o círculo branco mostra a presença de anteras de A. mearnsii.

Figure 1 - Insects caught racemes in A. mearnsii. $B, D, F$ and $H$ ) Details with an increase of 10 times in optical microscopy. 
A presença de besouros como potenciais dispersores de grãos de pólen em espécies do gênero Acacia já foi observada em outros estudos. Em A. senegal foi notado o coleóptero $M$. pustulata atuando como dispersor acidental de políades (TANDON et al., 2001). O hábito alimentar dessa espécie de coleóptero incluiu órgãos florais de A. senegal. O besouro, ao atacar as inflorescências, acabou por se contaminar com políades, auxiliando o fluxo de grãos de pólen ao buscar novos ramos florescidos para o forrageamento. Neste estudo foram vistos coleópteros (T. dimiatus, $T$. striatus e C. violasceus) forrageando inflorescências de acácianegra. Nos indivíduos capturados foram identificadas anteras e políades de $A$. mearnsii (Figura 1). Além disso, Tandon et al. (2001) identificaram políades de A. senegal em insetos da ordem Lepidoptera, embora o comportamento de voo exibido pelos insetos se limitasse ao estrato inferior da vegetação. Neste estudo com A. mearnsii, esse fato também foi observado em lepidópteros, os quais apenas sobrevoaram as copas, aparentemente para a atração sexual.

Em um estudo da biologia reprodutiva realizado na Tailândia com o híbrido de Acacia mangium e Acacia auriculiformis (SORNSATHAPORNKUL e OWENS, 1998), foi observada uma quantidade expressiva de políades no corpo de um coleóptero, Polydrusus sp. (família Curculionidae). Embora os autores tenham verificado grande quantidade de políades em indivíduos capturados dessa espécie de coleóptero, sua frequência foi considerada como ocasional na região de estudo. Ao contrário, nesta pesquisa $M$. suturalis aparece em grande frequência na região de estudo durante o período do florescimento de $A$. mearnsii. Os referidos autores observaram em abelhas A. mellifera e Ceratina sp. grande quantidade de políades na superfície corporal, além da expressiva frequência dessas espécies na região estudada.

Entre os principais fatores relacionados ao sucesso reprodutivo das espécies do gênero Acácia, encontrase a disponibilidade de polinizadores (GAOL e FOX, 2002). No caso da A. mearnsii, foi constatado que uma classe de vetores potenciais da polinização, as abelhas A. mellifera, foi encontrada em baixa frequência na área analisada. Uma das estratégias para contornar essa carência seria a introdução de caixas de abelhas em locais estratégicos que permitam a larga visitação na época de florescimento. Além disso, há a necessidade de manutenção nas áreas de plantio de fontes de néctar para as abelhas, uma vez que esse recurso é essencial para a sobrevivência das colmeias (STONE et al., 2003). Uma vez assegurado o recurso alimentar, provavelmente haverá também incremento na frequência de visitações de outras espécies de Hymenoptera. Quanto à frequência dos coleópteros, especialmente $M$. suturalis, Trachyderes sp. e $C$. violaceus, o aumento da frequência desses insetos nos plantios não é recomendado, visto que o hábito alimentar deles é essencialmente fitófago e, no caso de Trachyderes sp. e C. violaceus, a sua dieta incluiu os órgãos florais.

Neste estudo foram identificados os principais agentes envolvidos na polinização de $A$. mearnsii. No coleóptero $M$. suturalis, observou-se a maior quantidade de políades de acácia-negra aderidas ao corpo, bem como maior frequência desse inseto no plantio comercial analisado. Embora nas abelhas A. mellifera capturadas tenha sido quantificada grande quantidade de políades, sua frequência na área analisada foi considerada baixa. Outros insetos da ordem Hymenoptera foram observados com maior frequência que $A$. mellifera e com quantidade expressiva de políades de A. mearnsii aderidas, principalmente, nas asas. Uma das formas para contornar a baixa frequência de abelhas no local de estudo é a manutenção de fontes de néctar e a introdução de colmeias.

\section{REFERÊNCIAS}

ARCE-PÉREZ, R.; MORÓN, M. A. New species and new records of species of Macrodactylus Dejean (Coleoptera: Scarabaeidae: Melolonthinae: Macrodactyini) from Honduras and Nicarágua. Zootaxa, v.1012, p.23-37, 2005.

BERNHARDT, P.; KENRICK, J.; KNOX, R. B. Pollination biology and the breeding system of Acacia retinodes (Leguminosae: Mimosoideae). Annals of Missouri Botanical Garden, n.71, p.17-29, 1984.

CALDEIRA, M. V. W.; RONDON NETO, R.M.; SCHUMACHER, M. V. Conteúdo e exportação de micronutrientes em acácia-negra (Acacia mearnsii De Wild.) procedência Batemans Bay (Austrália).

Revista Árvore, v.27, n.1, p.9-14, 2003.

CASELÍN-CASTRO, S. et al. Incidencia de Macrodactylus nigripes Bates (Coleoptera: Melolonthidae) en Maíz y Haba en Tlaxcala, México. Agrociencia, v.37, n.3, p.291-297, 2003.

R. Árvore, Viçosa-MG, v.33, n.3, p.443-450, 2009 
CHARÃO, L. S. Efeito da Polinização por abelhas Apis mellifera $L$. na produção de sementes de Acacia mearnsii De Wild. 2000. 163f. Dissertação (Mestrado em Engenharia Florestal) - Universidade Federal de Santa Maria, Santa Maria, 2000.

GAOL, M. L.; FOX, J. E. D. Reproductive potential of Acacia species in the central wheatbelt: variation between years.

Conservation Science of Western Australian, v.4, n.3, p.147-157, 2002.

GRANT, J. E.; MORAN, G. F.; MONCUR, M. W. Pollination studies and breeding system in Acacia mearnsii. In: AUSTRALIAN TREE SPECIES RESEARCH IN CHINA, 1994, Camberra. Proceedings... Camberra: ACIAR, 1994. p.165-170.

KENRICK, J.; KNOX, R. B. Pollen development and cytochemistry in some Australian species of Acacia. Australian Journal of Botany, v.27, p.413-427, 1979.

MONCUR, M. W.; KLEINSCHMIDT, G.; SOMERVILLE, D. The role of Acacia and Eucalypt plantations for honey production. In: ADVANCES IN TROPICALACACIA, 1991, Bangladesh. Proceedings... Bangladesh: ACIAR, 1991.p.123-127.
PAULINO, A. F. et al. Distribuição do sistema radicular de árvores de acácia-negra oriundas de mudas produzidas em diferentes recipientes. Revista Árvore, v.27, n.5, p.605-610, 2003.

SORNSATHAPORNKUL, P.; OWENS, J. N. Pollination biology in a tropical Acacia hybrid (A. mangium Willd. x A. auriculiformis A. Cunn. ex Benth). Annals of Botany, v.81, p.631-645, 1998.

STONE, G.N. et al. Pollination ecology of acacias (Fabaceae, Mimosoideae). Australian Systematic Botany, v. 16, p.103-118, 2003.

TANDON, R.; SHIVANNA, K. R.; MOHAN-RAM, H. Y. Pollination biology and breeding system of Acacia senegal. Botanical Journal of the Linnean Society, v.135, n.3, p.251-262, 2001.

WAGNER, D. Pollen viability reduction as a potential cost of ant association for Acacia constricta (Fabaceae). American Journal of Botany, v.87, n.5, p.711-715, 2000.

WILLIAMS, R. N. et al. Development of an attractant for the Scarab Pest Macrodactylus subspinosus (Coleoptera: Scarabaeidae).

Journal of Economic Entomology, v.93, n.5, p.1480-1484, 2000. 